\title{
PEMODELAN DATA SEISMIK LINGKUNGAN VULKANIK
}

\author{
Muhammad Ghazalli, Amien Widodo, Firman Syaifuddin \\ Jurusan Teknik Geofisika, FTSP Institut Teknologi Sepuluh Nopember \\ e-mail:m.ghazalli@yahoo.com
}

\begin{abstract}
Abstrak. Eksplorasi hidrokarbon saat ini mengharuskan geosaintis untuk mencari area baru yang sebelumnya dianggap tidak menghasilkan hidrokarbon. Dengan ditemukannya rembesan minyak pada daerah vulkanik mengindikasikan adanya petroleum play aktif yang memiliki cadangan hidrokarbon. Ketidakmampuan gelombang seismik untuk menggambarkan bawah permukaan pada daerah vulkanik menjadikan dibutuhkannya pemodelan seismik. Pemodelan seismik akan memodelkan atau merekonstruksikan penjalaran gelombang seismik pada model geologi yang telah ditentukan, pada kasus ini model geologi yang digunakan adalah model geologi pada lingkungan vulkanik. Penelitian ini menggunakan 2 model, yang pertama adalah model "Kue Lapis" dan yang kedua adalah model "Serayu" yang merupakan model kompleks dari cekungan North Serayu di Jawa tengah. Kedua model tersebut memiliki lapisan basalt dengan tebal $200 \mathrm{~m}$ yang menutupi lapisan bawahnya yang menjadi target karena menyimpan cadangan hidrokarbon. Dari hasil pemodelan dapat dilihat fenomena gelombang ketika merambat melalui lingkungan vulkanik. Data hasil pemodelan kemudian direkonstuksikan ulang dengan menggunakan pengolahan data seismik menggunakan alur pengolahan seismik konvensional mulai dari geometri hingga migrasi. Hasil olahan tersebut akan dibandingkan dengan model yang telah dibuat dan dilakukan analisa. Dihasilkan bahwa dibutuhkan disain akuisisi yang khusus untuk lingkungan vulkanik karena keterbatasan gelombang untuk melakukan penetrasi pada lapisan tipis dan memiliki kontras kecepatan yang besar lalu pengaruh koreksi statik yang sangat mempengaruhi data dikarenakan elevasi topografi dan kemudian ditemukan fenomena multiple ketika gelombang melewati lapisan basalt dan berkurangnya resolusi seismik ketika melewati lapisan basalt dikarenakan gelombang cenderung diteruskan mengikuti hukum Fermat.
\end{abstract}

Kata Kunci: pemodelan seismik; lingkungan vulkanik; pengolahan data seismik

Abstract. Exploration hydrocarbon now requires geoscientist to find new territories formerly regarded not producing hydrocarbon. By the invention of oil seepage on volcanic regions indicates there is active petroleum play who has reserves of hydrocarbons beneath. Inability waves seismic to describe and give good image under the surface at volcanic regions made it is necessary to seismic modeling. This method will be modeling or reconstructing seismic waves propagation on the model of geology that has been specified, in this case, geology model to used is a geological model at the volcanic environment. This research using 2 model, the first is a model 'Kue Lapis' and the second is a model 'Serayu' that is the complex model of the North Serayu basin in Central Java. Both the model had the basalt with thick 200 meters that cover the lining of targeted who have hydrocarbon reserve. From the modeling could be seen the phenomenon of the seismic wave when spread through layers of volcanic. Synthetic data from modeling then reconstruct using seismic processing with conventional seismic processing from geometry to migration. After that, the processing result will be compared with the model that have been made and do the analysis. From the result we could see that it takes special design acquisition to volcanic environment due to limited wavelengths to do penetration on the thin layer and having great velocity contrast and also the influence of static correction that very affect the data because the variation of elevation topography, the last we could found there is multiple when seismic wave goes through basalt layers and reduced seismic resolution when passing through it because waves tend to continued in highvelocity layer followed by Fermat law.

Keywords: seismic modelling; volcanic environment; seismic data processing

\section{PENDAHULUAN}

Kebutuhan energi di Indonesia dan dunia terutama di bidang energi fosil mengharuskan kegiatan eksplorasi cadangan migas terus dilakukan.

Dengan semakin menipisnya cadangan pada petroleum sistem yang konvensional memunculkan ide-ide baru dengan adanya cadangan migas 
pada daerah yang dianggap tidak dapat memproduksi migas, yaitu area lingkungan batuan vulkanik.

Di pulau Jawa sendiri penemuan rembesan minyak dan gas paling banyak muncul di area vulkanik. Saking banyaknya rembesan minyak di area vulkanik sampai pernah memunculkan teori bahwa minyak dan gas itu memiliki asal magmatik (salah satu teori anorganik asal minyak yang pernah muncul pada zaman Hindia Belanda di Indonesia). Seiring berkembangnya pengetahuan lalu diketahui bahwa asal hidrokarbon adalah organik, yaitu dari zat renik organik (bakteri, plankton, ganggang) atau tumbuhan-tumbuhan di darat yang sebagian massanya menjadi komponen di batuan penggenerasi hidrokarbon (source rock) (Awang Satyana, 2015).

Berdasarkan itu, maka diduga bahwa di Jawa banyak batuan induk pengandung zat organik terkubur dan tertutup oleh lapisan tebal batuan vulkanik yang menutupinya. Batuan volkanik ini telah menekan dan menenggelamkan batuan induk ke kedalaman yang menyebabkan zat organik di dalam batuan induk menjadi matang dan berubah menjadi minyak dan gas, lalu sebagian migas ini naik ke permukaan melalui celah-celah atau patahanpatahan dan menjadi rembesan minyak/gas di permukaan (Awang Satyana,2015).

Tantangannya sekarang adalah teknologi pengambilan data (akuisisi) dan pengolahan data seismik (processing) sampai saat ini hampir tak mampu menembus lapisan tebal vulkanik untuk mengungkap konfigurasi lapisan batuan di bawah vulkanik (sub-vulcanic) dengan maksimal. Oleh karena itu dibutuhkan pemodelan data seismik untuk mengetahui dan memahami bagaimana respon gelombang seismik ketika menjalar melalui model geologi yang kompleks, dalam hal ini pada lingkungan batuan vulkanik.

\section{TINJAUAN PUSTAKA}

\section{Pemodelan Ke depan}

Pemodelan ke depan yang digunakan dalam penelitian ini adalah pemodelan gelombang akustik dalam medium isotropik. Untuk pemodelan akustik, properti medium dijelaskan sebagai sebaran ruang dengan parameter perambatan gelombang dari gelombang yaitu $v=(x 1, x 3)$ dan densitas $\rho(x 1, x 3)$. Persamaan gelombang akustik dijelaskan sebagai medan vektor dari pemindahan kecepatan $u$ dan medan skalar dari tekanan $p$, keduanya menghasilkan persamaan sebagai berikut.

$$
\begin{aligned}
& \frac{\partial u_{1}}{\partial t}=\frac{1}{\rho} \frac{\partial p}{\partial x_{1}} \\
& \frac{\partial u_{3}}{\partial t}=\frac{1}{\rho} \frac{\partial p}{\partial x_{3}} \\
& \frac{\partial p}{\partial t}=\rho v^{2}\left(\frac{\partial u_{1}}{\partial x_{1}}+\frac{\partial u_{3}}{\partial x_{3}}\right)
\end{aligned}
$$

selanjutnya, turunkan persamaan 1 dengan $x 1$, persamaan kedua dengan $\times 3$, dan persamaan ketiga dengan $t$, maka didapatkan.

$$
\begin{aligned}
& \frac{\partial^{2} u_{l}}{\partial t \partial x_{l}}=\frac{\partial \frac{\rho}{\rho}}{\partial x_{l}} \frac{\partial p}{\partial x_{l}}+\frac{1}{\rho} \frac{\partial^{2} p}{\partial x_{1}{ }^{2}} \\
& \frac{\partial^{2} u_{3}}{\partial t \partial x_{3}}=\frac{\partial \frac{\rho}{\partial x_{3}}}{\partial x_{3}}+\frac{\partial}{\rho} \frac{\partial^{2} p}{\partial x_{3}{ }^{2}} \\
& \frac{\partial^{2} p}{\partial t^{2}}=\rho v^{2}\left(\frac{\partial^{2} u_{l}}{\partial t \partial x_{1}}+\frac{\partial^{2} u_{3}}{\partial t \partial x_{3}}\right)
\end{aligned}
$$

dengan mensubtitusikan persamaan 4 dan 5 ke persamaan 6 , maka didapatkan persamaan akustik dengan notasi tekanan.

$\frac{\partial^{2} p}{\partial t^{2}}=p v^{2}\left[\left(\frac{\partial \frac{x}{p}}{\partial x_{1}} \frac{\partial p}{\partial x_{1}}+\frac{1}{\rho} \frac{\partial^{2} p}{\partial x_{1}^{2}}\right)+\left(\frac{\partial \frac{x}{p}}{\partial x_{3}} \frac{\partial p}{\partial x_{3}}+\frac{1}{\rho} \frac{\partial^{2} p}{\partial x_{3}^{2}}\right)\right]$

persamaan 7 dapat disederhanakan menjadi,

$$
\frac{\partial^{2} p}{\partial t^{2}}=v^{2}\left(\frac{\partial^{2} p}{\partial x_{1}}+\frac{\partial^{2} p}{\partial x_{3}}\right)+p v^{2}\left(\frac{\partial \frac{x}{p}}{\partial x_{1}} \frac{\partial p}{\partial x_{1}}+\frac{\partial \frac{1}{p}}{\partial x_{3}} \frac{\partial p}{\partial x_{3}}\right)
$$

dapat dilihat pada persamaan 7, terdapat persamaan yang menurunkan dengan densitas. Jika nilai tersebut mendekati 0 maka pada kasus ini akustik dan nilai skalar identik dengan tekanan. 
Perambatan gelombang bergantung kepada properti medium statik (tidak berubah seiring waktu). Beberapa properti yang mempengaruhi perambatan gelombang seismik adalah kecepatatan primer (Vp) dan kecepatan sekunder (Vs), densitas p) lalu properti tambahan seperti anisotropi (Parameter Thompson, atenuasi, dan absorpsi).

\section{Parameter Pemodelan}

Dalam pemodelan ke depan parameter yang dirasa signifikan adalah jumlah sumber, jumlah geophone, dan besar grid. Perhitungan yang dilakukan akan menghitung dan memodelkan respon seismik dari setiap sumber, semakin besar jumlah sumber maka akan semakin membutuhkan waktu untuk perhitungan. Selanjutnya yang mempengaruhi adalah besar grid sesuai dengan persamaan yang ada pada (Virieux, 1986). Dapat dilihat pada persamaan 9 .

$\frac{\partial^{2} U(x, t)}{\partial x^{2}}=b(x) \frac{\partial}{\partial x}\left(\frac{\partial u(x, t)}{\partial t}\right)$

persamaan 9 adalah persamaan gelombang, jika diasumsikan variable $\tau$ dan $U$ (stress \& displacement) sepanjang lintasan didistribusikan dengan notasi $i=\ldots,-2,-1,0,1,2, \ldots$ lalu variabel $\tau$ dan $U$ ditentukan dengan posisi genap ganjil sepanjang lintasan. Berikut ilustrasinya. dengan $\Delta \mathrm{x}, \Delta \mathrm{t}->0$, dan ketika persamaan 10 dan 11 diturunkan 2 kali terhadap $\mathrm{t}$, maka

$\frac{\partial^{2} \tau(x, t)}{\partial x^{2}}=a(x) \frac{\partial}{\partial x}\left(\frac{\partial U(x, t)}{\partial t}\right)$

$\frac{\partial^{2} U(x, t)}{\partial x^{2}}=b(x) \frac{\partial}{\partial x}\left(\frac{\partial \pi(x, t)}{\partial t}\right)$

variabel $\mathrm{Ab}$ bi menerangkan properti (konstan dalam waktu t) tersebar sepanjang sumbu $x$. jika nilai dari turunan dasar $\Delta x$ bernilai tetap (grid) dan pertambahan waktu $\Delta \mathrm{t}$ juga konstan, maka nilai $\mathrm{Ab}$ bi dapat ditentukan.

$A_{\mathrm{i}}=a_{\mathrm{i}} \frac{\Delta \mathrm{t}}{\Delta \mathrm{x}}$ atau $A_{\mathrm{i}}=\frac{a_{i}}{G}$

$B_{\mathrm{i}}=b_{\mathrm{i}} \frac{\Delta \mathrm{t}}{\Delta \mathrm{x}} \operatorname{atau} B_{\mathrm{i}}=\frac{\vec{b}_{\mathrm{i}}}{\mathrm{G}}$

dengan $\mathrm{G}=\Delta \mathrm{x} / \Delta \mathrm{t}, \mathrm{G}$ mendefinisikan skala konstan dengan dimensi kecepatan $(\mathrm{m} / \mathrm{sec})$, kemudian pada persamaan 9 akan stabil ketika $\mathrm{Vp}[\max ]<\mathrm{G}$, dengan $\mathrm{Vp}$ [max] adalah nilai maksimal kecepatan $\mathrm{p}$ pada grid. Selanjutnya $G=\Delta t / \Delta d$, dimana $\Delta t$ adalah tahapan komputasi (1 tahapan $\Delta \mathrm{t} / 2$ ) dan $\Delta \mathrm{d}$ adalah turunan ( 1 sell $\Delta d / w)$. Kemudian untuk menghitung limitasi kecepatan perhitungan,

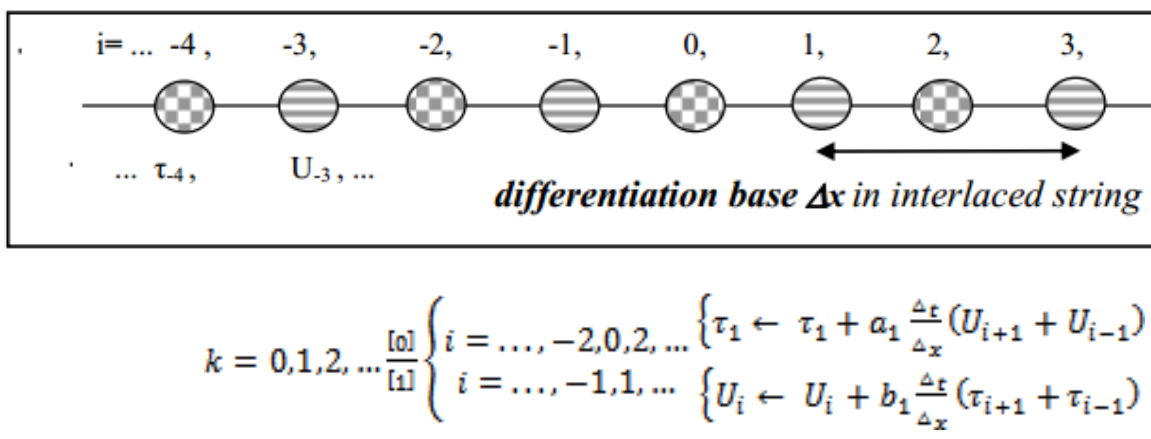

$\Delta d=\frac{V p[\text { min }]}{\mathrm{F}[\text { pick }] f_{\text {Basewave }}}$ lalu jika persamaan 10 diintegralkan,

$$
\begin{aligned}
& \tau(x, t)=a(x) \int_{0}^{t} \frac{\partial U(x, t)}{\partial x} d t \\
& U(x, t)=b(x) \int_{0}^{t} \frac{\partial \tau(x, t)}{\partial x} d t
\end{aligned}
$$

lalu untuk menghitung durasi waktu 1 kali komputasi (pemodelan 1 sumber) 
$\Delta \mathrm{t}=\frac{\Delta \mathrm{d}}{\nabla_{\mathrm{p}[\mathrm{max}]} / \text { Stability }}$

dengan $V p[m i n]$ adalah nilai $V p$ minimum, $V p[\max ]$ adalah nilai Vp maksimum, F[pick] adalah nilai frekuensi yang diberikan pada sumber, dan stability adalah sqrt $(2)+1 / 2 /$ Basewave mendekati 1.5 stability konstan.

\section{METODOLOGI}

Data yang digunakan dalam tugas akhir ini adalah data sintetik dengan menggunakan model geologi pada lingkungan batuan vulkanik. Perangkkat lunak yang digunakan adalah Pemodelan Seismik untuk melakukan forward modelling (pembuatan model) dan Pengolahan Data Seismik untuk pengolahan data sintetik. Pengolahan data dapat dijelaskan dengan diagram alir pada Gambar 15 dan Gambar 16.

Tahap pertama adalah membuat model geologi yang selanjutnya akan dilakukan akuisisi seismik secara forward modelling sehingga didapatkan data sintetik. Model geologi yang digunakan diusahakan mendekati model geologi lapangan sehingga diperlukan referensi lingkungan pengendapan di daerah batuan Vulkanik (Facies Vulkanik) sebagai wawasan pembuatan model geologi (jenis batuan, stuktur geologi dan morfologi) lalu dibutuhkan studi literatur untuk mengaitkan kondisi geologi yang diinginkan dengan properti fisis batuan seperti Kecepatan $\mathrm{P}$ dan densitas.

Setelah didapatkan model geologi lingkungan vulkanik yang diinginkan selanjutnya diberikan parameter akuisisis seperti jumlah channel, jumlah titik penembakan, near offset, far offset, lama perekaman, sampling time, dan frekuensi yang diberikan. Parameter akuisisi ini digunakan untuk tahapan selanjutnya yaitu forward modelling yang akan menghasilkan sintetik seismogram. Data yang dihasilkan akan memiliki domain waktu dan merupakan data mentah sehingga diperlukan pengolahan data seismik. Hasil pengolahan data seismik ini yang kemudian akan dianalisa.

\section{HASIL DAN PEMBAHASAN \\ Model Geologi Sederhana}

Model geologi sederhana merupakan model yang digunakan untuk melihat sifat perambatan gelombang seismik hasilnya ketika sudah diolah. Model yang digunakan adalah model lapisan tanpa struktur dengan memasukkan lapisan batuan basalt untuk melihat perambatan gelombang pada lapisan tersebut.

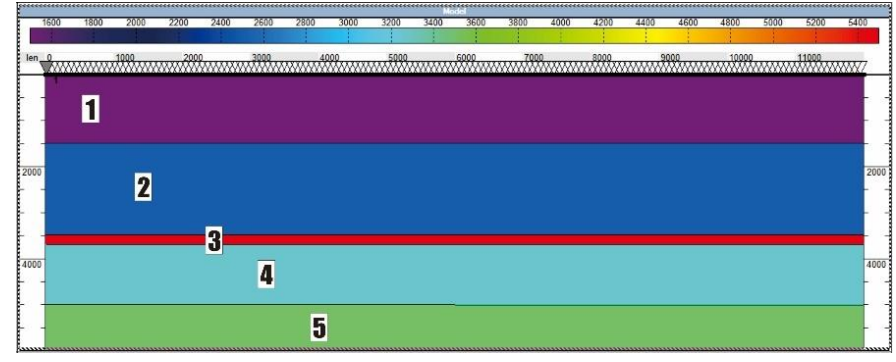

Gambar 1. Model Geologi "Kue Lapis" tanpa Struktur dengan Dimensi Panjang 12 km dan Kedalaman Maksimum $6 \mathrm{~km}$.

Tabel 1. Parameter Fisis Model Kue Lapis.

\begin{tabular}{|c|l|r|c|c|}
\hline $\begin{array}{c}\text { Lapisan } \\
\text { ke }\end{array}$ & \multicolumn{1}{|c|}{$\begin{array}{c}\text { Tipe } \\
\text { Lapisan }\end{array}$} & $\begin{array}{r}\text { VP } \\
(\mathrm{m} / \mathrm{s})\end{array}$ & $\begin{array}{c}\text { Densitas } \\
\left(\mathrm{kg} / \mathrm{m}^{3}\right)\end{array}$ & $\begin{array}{c}\text { Ketebalan } \\
(\mathrm{m})\end{array}$ \\
\hline 1 & Sandstone & $\begin{array}{r}1 \\
500\end{array}$ & 1970 & 1500 \\
\hline 2 & Sandstone & $\begin{array}{r}2 \\
500\end{array}$ & 2200 & 2000 \\
\hline 3 & Basalt & $\begin{array}{r}5 \\
500\end{array}$ & 2575 & 200 \\
\hline 4 & Sandstone & $\begin{array}{r}3 \\
250\end{array}$ & 2237 & 1400 \\
\hline 5 & Sandstone & 3 & 2275 & 1000 \\
\hline
\end{tabular}

\section{Disain Akuisisi Model Kue Lapis}

Beberapa hal yang harus diperhatikan dalam menentukan disain akuisisi adalah ketebalan lapisan dan kedalaman lapisan target. Digunakan frekuensi sebesar $5 \mathrm{~Hz}$ dikarenakan hasil "Test Run" yang akan dibahas pada bab 4.2. Penentuan far offset ditentukan kurang lebih 2 kali kedalaman, dikarenakan target memiliki kedalaman $6 \mathrm{Km}$ maka far offset yang digunakan sejauh $12 \mathrm{Km}$. Penentuan shot dan receiver interval dihasilkan dari 
penggunaan grid yang digunakan, dikhawatirkan kualitas data akan menjadi jelek ketika interval geophone tidak mengikuti 2 kali lebar grid.

Tabel 2. Parameter Akuisisi Model Kue Lapis.

\begin{tabular}{|l|l|}
\hline Grid 20 meter & $\begin{array}{l}\text { Frekuensi } 5 \mathrm{~Hz} \text { Wavelet } \\
\text { Ricker }\end{array}$ \\
\hline Shot Interval $80 \mathrm{~m}$ & Total Shot 150 \\
\hline Receiver Interval $40 \mathrm{~m}$ & Total Receiver 301 \\
\hline Record Length 7 sekon & Sampling Interval $2 \mathrm{~ms}$ \\
\hline
\end{tabular}

\section{Seismic Gather Model Kue Lapis}

Model geologi yang telah memiliki parameter fisis kemudian dilakukan forward modelling untuk melihan respon seismiknya. Dikarenakan model yang digunakan tanpa struktur, maka respon seismiknya memiliki penurunan waktu atau efek hiperbolik yang bagus. Respon yang tebal mengindikasikan terjadinya refleksi dengan lapisan. Ada beberapa respon tipis pada bagian time besar diasumsikan sebagai noise, akan dijelaskan pada bagian selanjutnya.

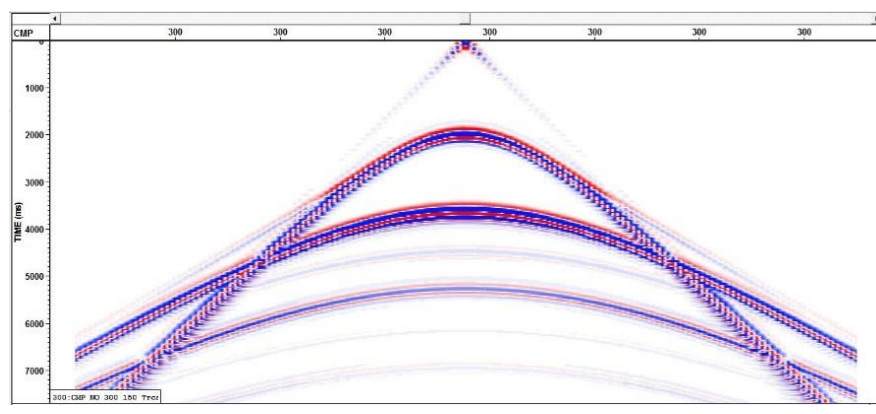

Gambar 2. CMP Gather 300 (Tengah Lintasan dengan Fold Terbanyak).

\section{Analisa}

Pada Gambar 4, kemenerusan amplitudo kuat dapat diasumsikan sebagai bidang perlapisan. Respon gelombang seismik pada bidang perlapisan 1 dan 2 terlihat normal dan kuat karena merupakan bidang perlapisan normal antara sandstone dan tidak memiliki kontras Vp yang besar.

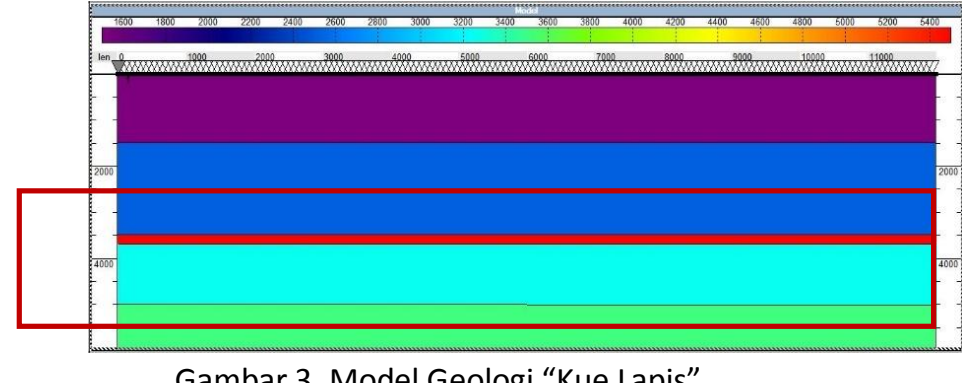

Gambar 3. Model Geologi "Kue Lapis".

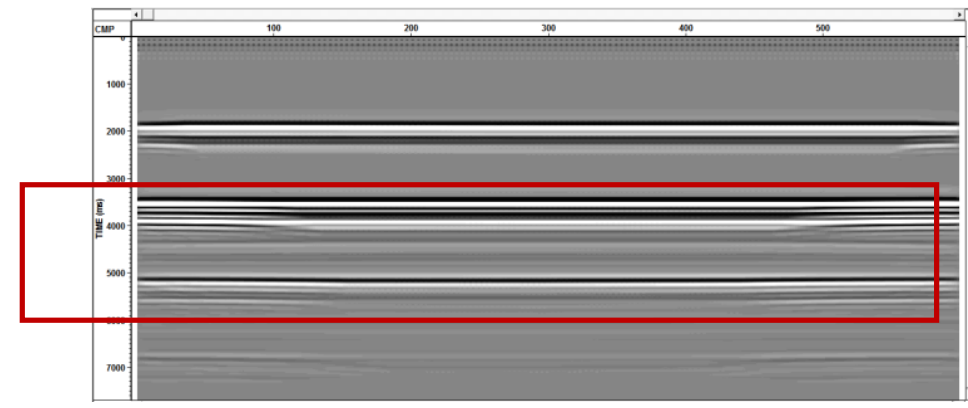

Gambar 4. Hasil Stack Seismic Model Geologi

"Kue Lapis".

Tetapi ketika gelombang seismik merambat ke lapisan selanjutnya yaitu pelapisan antara sandstone dan basalt terlihat respon seismik yang terekam memiliki reduksi energi yang besar dapat dibuktikan dengan menipisnya warna kemenerusan amplitudo dibawah lapisan basalt yang memiliki dua lapisan sandstone. Hal ini dikarenakan ketika gelombang merambat melalui bidang pelapisan dengan kontras kecepatan (kontras impedan) yang besar akan meredam gelombang yang akan ditransmisikan dan cenderung meneruskan gelombang sehingga akan direfleksikan kembali sesuai dengan Hukum Fermat dimana gelombang selalu mencari waktu tercepat untuk merambat.

Selanjutnya dapat dilihat pula terjadinya banyak even multiple yang diakibatkan oleh terjebaknya gelombang seismik karena kontras kecepatan antara lapisan batuan pasir dibawah dengan lapisan basalt yang meng-cover di atasnya. Ketika ada even berulang pada time yang tidak sewajarnya maka dapat di asumsikan sebagai multiple. Noise ini dapat direduksi dengan berbagai macam filter yang sudah tersedia. 


\section{Model Geologi Kompleks}

Model Geologi yang digunakan adalah hasil modifikasi dari penampang Geologi North Serayu Basin. Model geologi ini digunakan karena memiliki petroleum play mulai dari source rock, reservoir, trap, dan seal.

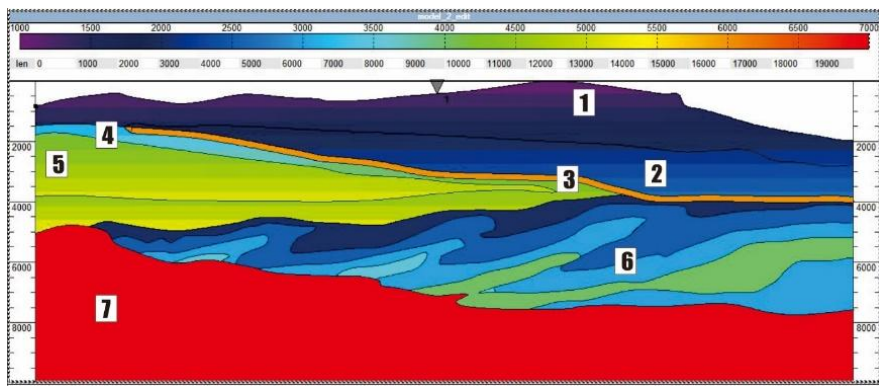

Gambar 5. Model "Serayu", Merupakan Modifikasi dari Skema North Serayu Basin dan Telah Diberikan Properti Fisis di Setiap Lapisan yang Didefinisikan. Memiliki Dimensi Panjang $20 \mathrm{Km}$ dengan Kedalaman $10 \mathrm{Km}$. Memiliki Elevasi Berkisar 0 Meter Hingga 1000 Meter.

Tabel 3. Properti fisis Model Serayu.

\begin{tabular}{|c|c|c|c|c|}
\hline $\begin{array}{l}\text { Lapisan } \\
\text { ke }\end{array}$ & $\begin{array}{c}\text { Tipe } \\
\text { Lapisan }\end{array}$ & $\begin{array}{l}\text { VP } \\
(\mathrm{m} / \mathrm{s})\end{array}$ & $\begin{array}{c}\text { Densitas } \\
\left(\mathrm{kg} / \mathrm{m}^{3}\right)\end{array}$ & $\begin{array}{c}\text { Ketebalan } \\
\text { (m) }\end{array}$ \\
\hline 1 & Soil & $\begin{array}{c}1000 \\
- \\
1800\end{array}$ & 1565 & 4000 \\
\hline 2 & $\begin{array}{c}\text { Batuan } \\
\text { Pasir }\end{array}$ & 2000 & 2010 & 1000 \\
\hline 3 & Basalt & 6000 & 2650 & 200 \\
\hline 4 & $\begin{array}{c}\text { Fasies } \\
\text { Vukanik }\end{array}$ & $\begin{array}{c}3000 \\
- \\
5000\end{array}$ & 2200 & 3400 \\
\hline 5 & $\begin{array}{c}\text { Fasies } \\
\text { Vukanik }\end{array}$ & $\begin{array}{c}4000 \\
- \\
5000\end{array}$ & 2350 & 2000 \\
\hline 6 & Sandstone & $\begin{array}{c}2000 \\
- \\
3000\end{array}$ & 2200 & 3500 \\
\hline 7 & $\begin{array}{l}\text { Basemen } \\
\text { Vulkanik }\end{array}$ & 7000 & 2970 & 3000 \\
\hline
\end{tabular}

\section{Desain Akuisisi}

Setelah didapatkan model yang akan digunakan kemudian dilakukan desain akuisisi, hal

ini dilakukan untuk mendapatkan data yang diinginkan dengan mempertimbangkan berbagai kondisi seperti ketebalan lapisan, kedalaman lapisan target, dan sebagainya. Untuk penentuan desain akuisisi dan parameter akuisisi dilakukan 4 kali tes dengan merubah beberapa parameter sebagai berikut. Tiap tes dilakukan 1 kali shot pada tengah model untuk melihat kualitas data, semua test run menggunakan model pada Gambar 5 dengan panjang lintasan $20 \mathrm{Km}$.

Tabel 4. Paramater Akuisisi Test Run 1.

\begin{tabular}{|l|l|}
\hline Grid 10 meter & Frekuensi $30 \mathrm{~Hz}$ \\
\hline Shot Interval $40 \mathrm{~m}$ & Total Shot 501 \\
\hline Receiver Interval $20 \mathrm{~m}$ & Total Receiver 1001 \\
\hline
\end{tabular}

Tabel 5. Paramater Akuisisi Test Run 2.

\begin{tabular}{|l|l|}
\hline Grid 15 meter & Frekuensi $30 \mathrm{~Hz}$ \\
\hline Shot Interval $60 \mathrm{~m}$ & Total Shot 175 \\
\hline Receiver Interval $30 \mathrm{~m}$ & Total Receiver 661 \\
\hline Durasi 1 shot 26 menit & Estimasi full shot 72 jam. \\
\hline
\end{tabular}

Tabel 6. Paremeter Akuisisi Test Run 3.

\begin{tabular}{|l|l|}
\hline Grid 20 meter & Frekuensi $30 \mathrm{~Hz}$ \\
\hline Shot Interval $80 \mathrm{~m}$ & Total Shot 131 \\
\hline Receiver Interval 40m & Total Receiver 500 \\
\hline Durasi 1 shot 14 menit & $\begin{array}{l}\text { Estimasi full shot 30,5 } \\
\text { jam. }\end{array}$ \\
\hline
\end{tabular}

Tabel 7. Paremeter Akuisisi Test Run 4.

\begin{tabular}{|l|l|}
\hline Grid 25 meter & Frekuensi $30 \mathrm{~Hz}$ \\
\hline Shot Interval $100 \mathrm{~m}$ & Total Shot 105 \\
\hline Receiver Interval $50 \mathrm{~m}$ & Total Receiver 400 \\
\hline Durasi 1 shot 12 menit & Estimasi full shot 21 jam. \\
\hline
\end{tabular}

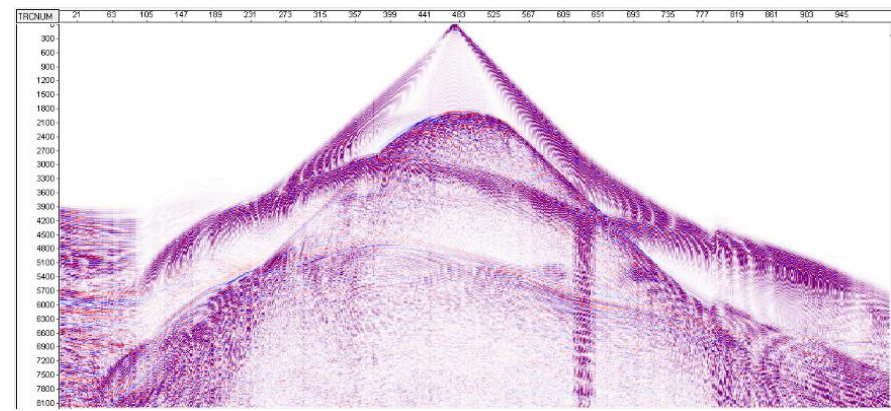

Gambar 6. Hasil Test Run 1. 


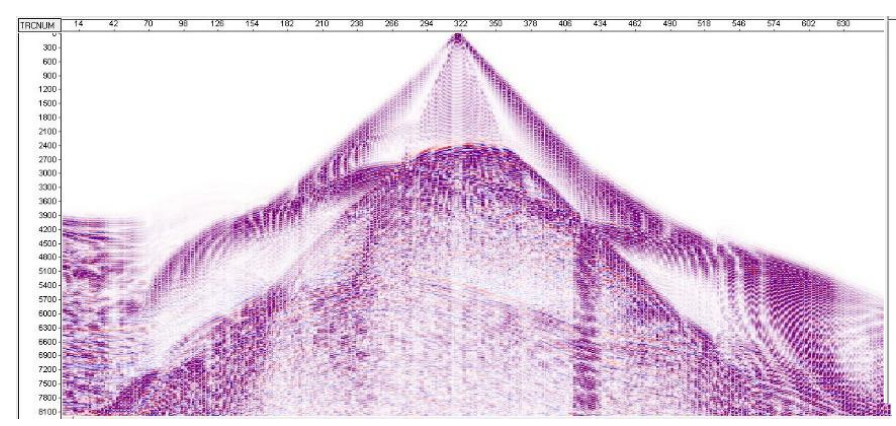

Gambar 7. Hasil Test Run 2.

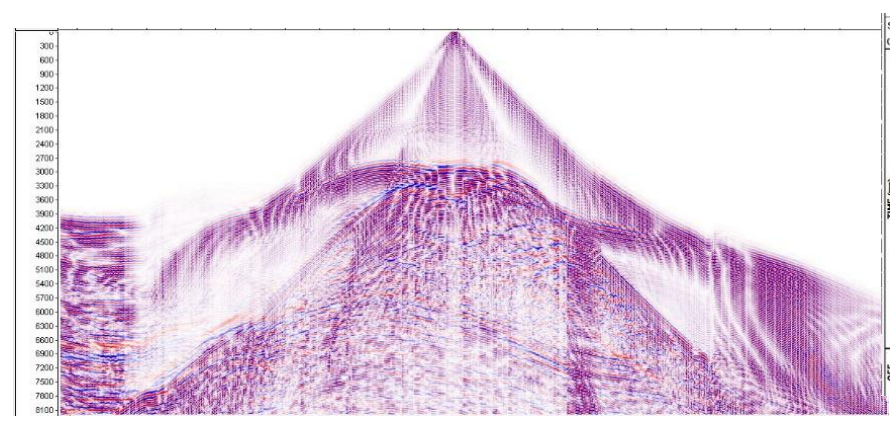

Gambar 8. Hasil Test Run 3.

Beberapa parameter yang mempengaruhi durasi penghitungan pemodelan atau limitasi kecepatan perhitungan sebagai berikut,

$$
\Delta \mathrm{d}=\frac{\mathrm{Vp}[\mathrm{min}]}{\mathrm{F}[\mathrm{pick}] / \text { Basewave }}
$$

Ialu untuk durasi waktu 1 kali komputasi (pemodelan dengan satu sumber)

$$
\Delta \mathrm{t}=\frac{\Delta \mathrm{d}}{\nabla_{\mathrm{p}[\mathrm{max}] / \text { Stability }}}
$$

Dengan $V p[m i n]$ adalah nilai $V p$ minimum, $\mathrm{Vp}[\mathrm{max}]$ adalah nilai $\mathrm{Vp}$ maksimum, F[pick] adalah nilai frekuensi yang diberikan pada sumber, dan stability adalah sqrt (2) $+1 / 2$ /Basewave mendekati 1.5 - stability konstan. Sehingga ketika diberikan Vp yang besar dan frekuensi yang rendah maka durasi perhitungan akan semakin panjang karena berbanding terbalik.

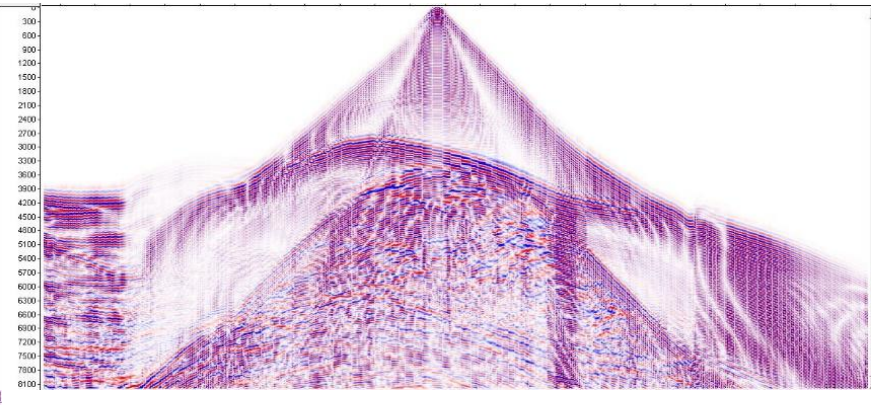

Gambar 9. Hasil Test Run 4.

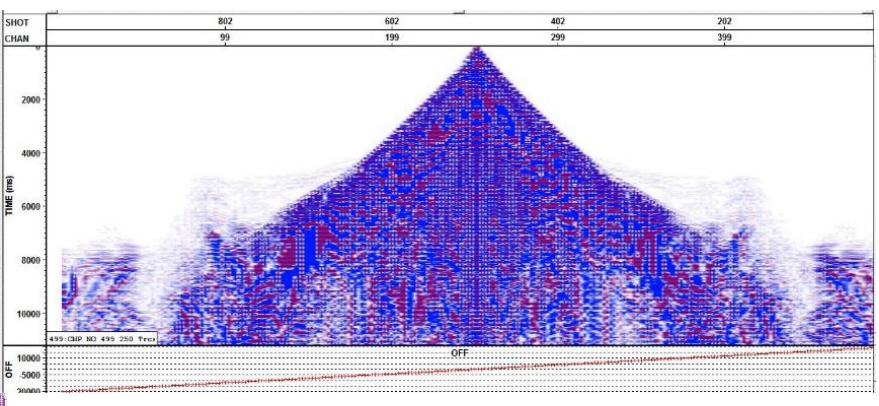

Gambar 10. Seismic Section pada cmp 500 dengan Menggunakan Frekuensi Shot Sebesar $30 \mathrm{~Hz}$.

Terlihat minimnya even parabolik pada far offset yang dapat menyebabkan minimnya penggambaran pada even refleksi yang dalam.

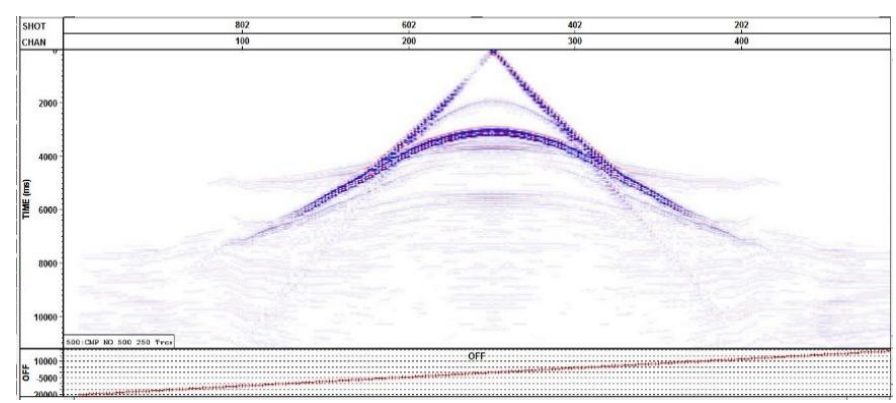

Gambar 11. Seismic Section pada cmp 500 dengan Menggunakan Frekuensi Shot Sebesar $5 \mathrm{~Hz}$.

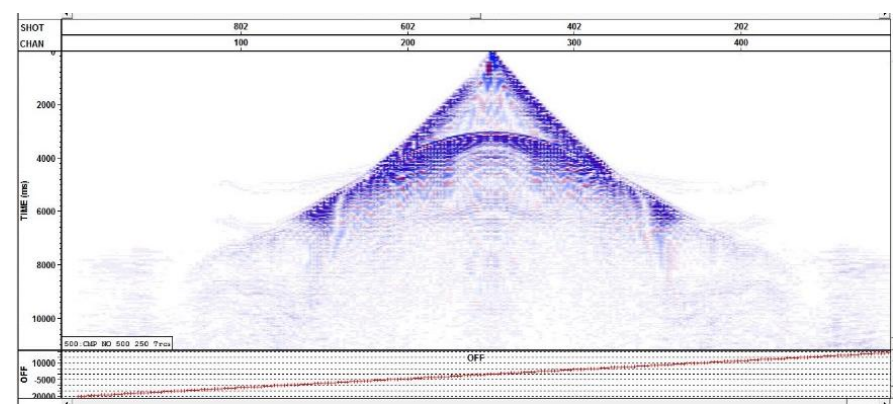

Gambar 12. Seismic Section pada cmp 500 dengan Menggunakan Frekuensi Shot Sebesar $10 \mathrm{~Hz}$. 
Pemilihan frekuensi shot harus memperhatikan berbagai faktor, jika frekuensi yang diberikan tinggi maka akan memberikan energy yang besar yang berakibat amplitude yang terekam akan besar, hal ini bagus tetapi pemilihan frekuensi yang tinggi memiliki resiko pendeknya panjang gelombang sehingga sulit untuk melakukan penetrasi pada lapisan yang dalam. Sebaliknya, frekuensi rendah memiliki panjang gelombang yang lebih panjang sehingga dapat melakukan penetrasi pada lapisan dalam. Dengan pertimbangan itu dan melihat hasil pemodelan pada Gambar 10, 11, dan 12 maka dipilih frekuensi yang akan digunakan sebesar $5 \mathrm{~Hz}$.

\section{Analisa Geologi Kompleks}

Gambar 14 merupakan hasil pengolahan data seismik dimulai dari geometri hingga residual statik 2.

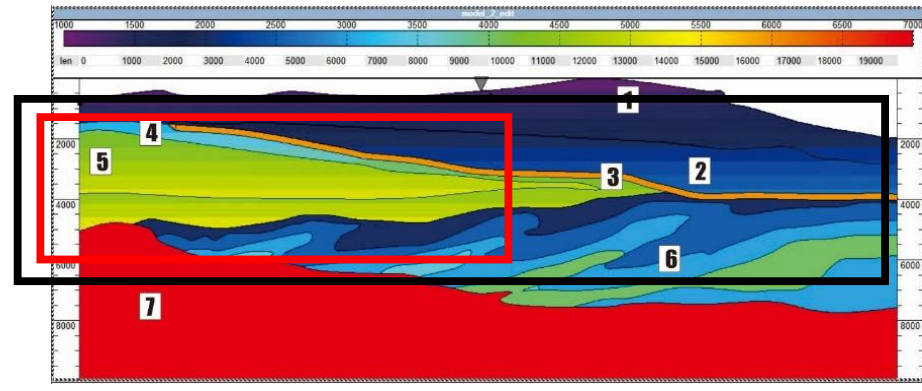

Gambar 13. Model Serayu yang Akan Dibandingkan dengan Hasil Penampang Seismik.

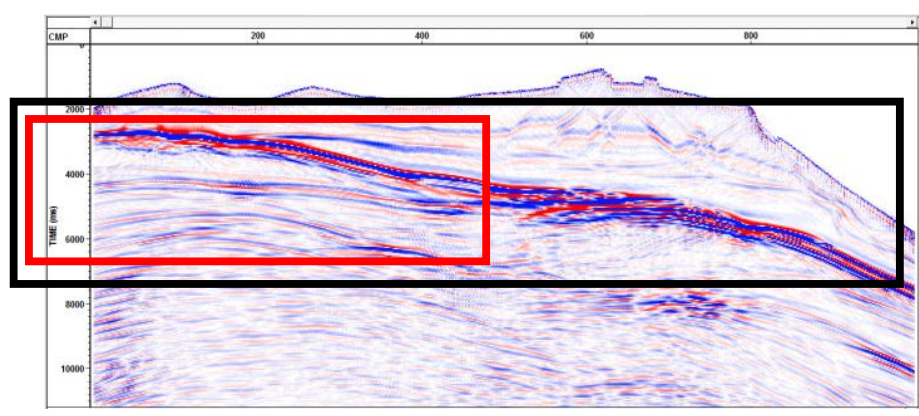

Gambar 14. Hasil Penampang Seismik Hasil Residual Statik 2.

Gambar di atas disandingkan untuk dilihat perbedaannya, model "Serayu" pada Gambar 12 merupakan model yang akan didekati dengan menggunakan pemodelan seismik dan direkonstruksi ulang menggunakan pengolahan data seismik yang ditampilkan pada Gambar 14.
Kemenerusan reflektor kuat pada Gambar 14 ditunjukkan dengan kotak hitam di asumsikan sebagai batas antara lapisan batuan pasir bagian atas dengan lapisan basalt dikarenakan memiliki kemenerusan yang mirip dengan model. Sehingga di asumsikan reflektor kuat pada Gambar 14 adalah lapisan basalt.

Selanjutnya terlihat reflektor yang membentuk lapisan sama seperti vulkanik facies (ditunjukkan dengan kotak merah) dan batas antara vulkanik facies dengan batuan dasar (batuan beku ditunjukkan dengan nomor 7). Di samping kedua fenomena tersebut, pada lapisan target tidak terlihat adanya reflektor yang mirip dengan zona thrusi. Hal ini disebabkan ketidakmampuan gelombang seismik untuk melakukan penetrasi melewati lapisan basalt tersebut. Sama seperti pada model "Kue Lapis" gelombang seismik cenderung diteruskan pada lapisan basalt dikarenakan perbedaan kecepatan yang sangat kontras mengikuti hukum Fermat bahwa gelombang menjalar dari satu titik ke titik lain melalui jalan tersingkat waktu penjalarannya.

\section{PENUTUP}

\section{Simpulan}

- Rentang sinyal frekuensi yang terekam sebesar $2 \mathrm{~Hz}-6 \mathrm{~Hz}$ sangat kecil dikarenakan diperlukan panjang gelombang yang besar sehingga diharapkan mampu melewati lapisan basalt yang memiliki ketebalan $200 \mathrm{~m}$.

- Terdapat fenomena multiple pada kedua model dilihat dari respon seismik dibawah lapisan basalt dan teredamnya gelombang dikarenakan kontras kecepatan yang besar.

- Elevasi menjadi faktor penting yang mempengaruhi kualitas data dikarenakan posisi shot dan receiver yang tidak sama pada seluruh lintasan. Diperlukan koreksi statik yang baik untuk meminimalisir efek tersebut.

- Pemodelan seismik baik digunakan untuk mendesain survei pada lingkungan vulkanik untuk mengetahui hasil perekaman dan 
sebagai bahan uji kualitas data bila memiliki informasi geologi pada lapangan survei.

\section{Saran}

- Pengolahan data yang dilakukan tidak dapat disamakan dengan pengolahan data pada kondisi secara umum (lapisan sedimen) seperti yang digunakan dalam penelitian ini. Diperlukan perlakuan khusus dikarenakan frekuensi yang digunakan sangat kecil.

- Pemodelan gelombang seismik dapat di lakukan pada sifat medium lain yang lebih kompleks sehingga menghasilkan simulasi gelombang seismik yang mendekati kondisi asli di lapangan misalnya pada medium elastik isotropik.

\section{DAFTAR PUSTAKA}

Bronto, S., 2006. Fasies Gunung Api dan Aplikasinya. Bandung. Jurnal Geologi Indonesia. V. 1 No. 2 Juni 2006, h. 59-71.

Hakim, N., 2007. Simulasi Gelombang Seismik untuk Model Sesar dan Lipatan pada Medium Akustik dan Elastik Isotropik. Bandung. Program Studi Teknik Geofisika ITB.

Hannsen, P., 2002. The Influence of Basalt Layer on Seismic Wave Propagation. Departement of Geology and Geophysics, Universityof Edinburgh.

Holford, S.P., N. Schofield, J.D. Macdonald, I.R. Duddy, and P.F. Green, 2012, Seismic Analysis of Igneous Systems in Sedimentary Basins and Their Impacts on Hydrocarbon Prospectivity: examples from the southern Australian margin: The APPEA Journal. V. 52 , p. 52.

Jackson, Christopher A.L., 2013, The Impact of Igneous Intrusions and Extrusions on Hydrocarbon
Prospectivity in Extensional Settings: A 3D Seismic Perspective. Search and Discovery Article \#41168, Department of Earth Science and Engineering, Imperial College, London, UK.

Klarner, Sabine \& Olaf K., 2013, Identification of PaleoVolcanic Rocks on Seismic Data. PGS Reservoir \& Klarenco, Germany.

Klarner, Sabine \& Olaf K., 2013, Identification of PaleoVolcanic Rocks on Seismic Data. PGS Reservoir \& Klarenco, Germany.

Prakoso, P., 2009. Migrasi Data Seismik 3D Menggunakan Metode Kirchoff Pre-Stack Depth Migration (Kirchoff PSDM) pada Lapangan Nirmala Cekungan Jawa Barat Bagian Utara. 2009. Departemen Fisika FMIPA Universitas Indonesia.

Rateau, R., Schofield, N. \& Smith, M., 2013. The Potential Role of Igneous Intrusions on Hydrocarbon Migration. West of Shetland, Petroleum Geoscience, in press.

Rohrman, M., 2007. Prospectivity of Volcanic Basins; Trap Delineation and Acreage De-Risking: AAPG Bulletin. V. 91/6, p. 915-939.

Satyana, A.H., 2015. Subvolcanic Hydrocarbon Prospectivity of Java: Opportunities and Challenge. Proceedings Indonesian Petroleum Association, 39th Annual Convention and Exhibition, Jakarta, May 2015.

Taib, M.I.T., 2002. Seismik Refraksi, Jurusan Teknik Geofisika, ITB.

Virieux, J., 1986. Wave Propagation in Heterogeneous Media: Velocity-stress Finite Difference Method: Geophysics, 51, 901. 


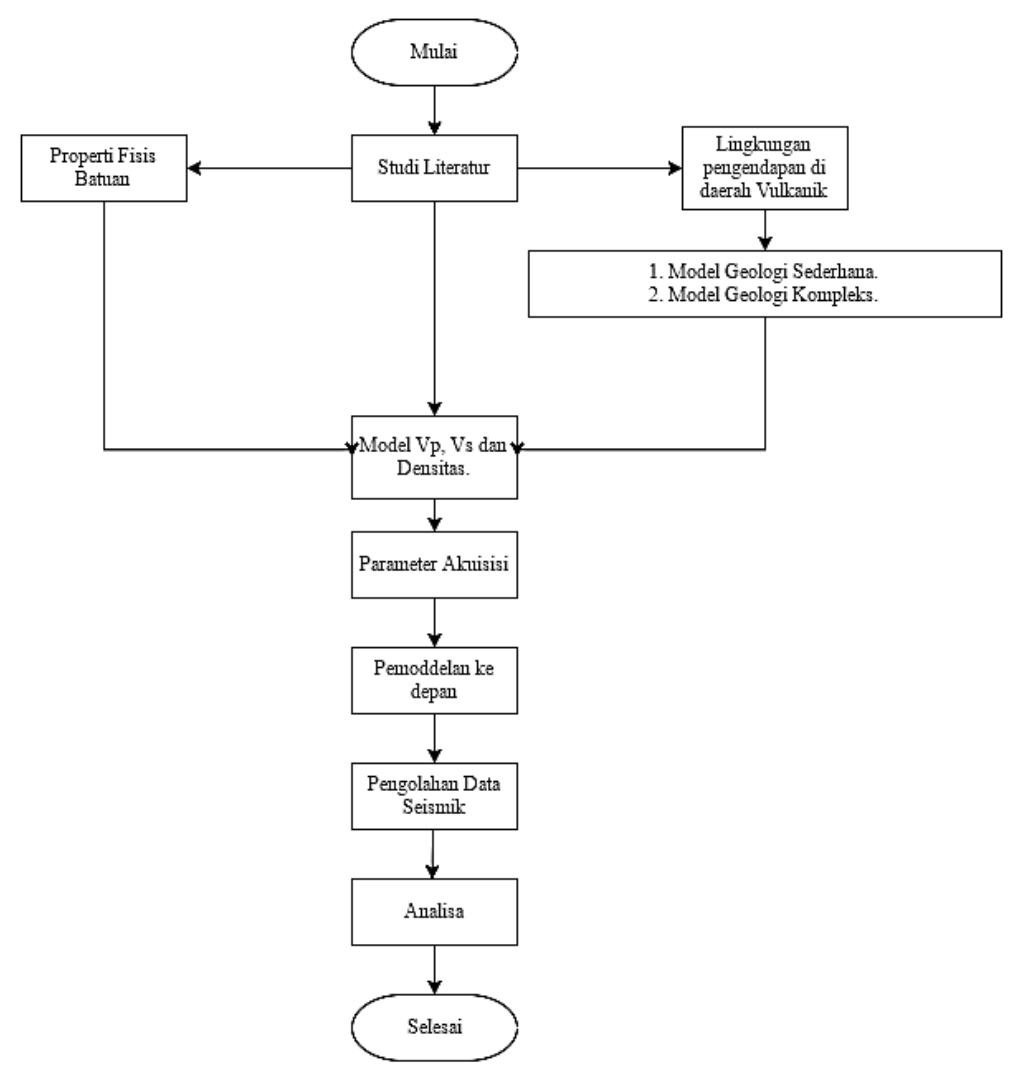

Gambar 15. Alur Pengolahan Data.

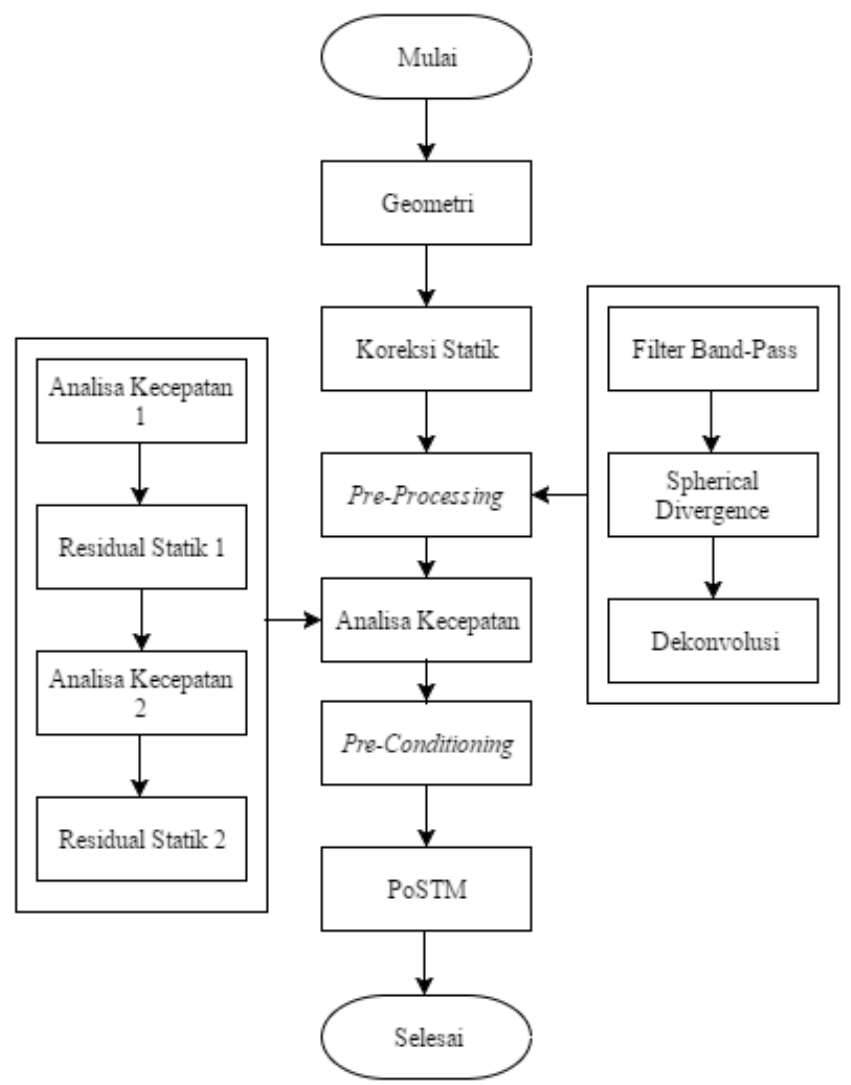

Gambar 16. Alur Processing Data Seismik. 